The Geneva Papers on Risk and Insurance, 18 (No. 69, October 1993), 432-438

\title{
Consumer Protection and Insurance Supervision
}

\author{
by Peter Pfund*
}

\section{Introduction}

Concurrently with this 20 th General Meeting of the Geneva Association, the 13th Conference of European Supervisory Authorities is commencing in Copenhagen. With only a few exceptions, all Europe's supervisory authorities are meeting there to exchange ideas. Delegations from the OECD and EC will also participate. Amongst the various topics for discussion there is one that will doubtless create a great deal of interest. Its (shortened) title is:

"Methods of solvency control in non-life insurance and the possible application of early warning systems."

From this subject, it can be seen that the supervisory authorities remain intensely preoccupied with solvency control, even after over a hundred years of insurance industry supervision in Europe. I would even go so far as to say that this is more relevant today - when Europe is celebrating the triumph of liberalisation and deregulation - than at any other time since the Second World War. Those countries for whom product control has up till now been an essential element of supervision are finding these changes particularly difficult. The path towards solvency supervision is thorny - both in theory and in practice. This applies not only to the supervisor, but to the insurance industry and the consumers as well. Where the supervision has until now been based on receiving the information needed to approve a product and thereby gaining a good picture of the technical side of the insurer's business, there is now uncertainty. The adoption of the English system of solvency supervision will result in an appreciable loss of information for the continental supervisor. It has to be asked whether supervision is conceivable without this information or whether the missing information can be obtained by other means. To anticipate a part of my conclusions, it is my opinion that the truth lies - as is often the case - somewhere in between, or to put it another way, involves all aspects. We in Switzerland believe that though we will have to obtain part of the missing information by other means, we must also give supervision a new orientation, based in part on new concepts.

* Director of the Federal Office for Insurance Supervision, Bern, Switzerland. Revised panel contribution to the 20th General Meeting of the Geneva Association on 7/8 June 1993 in Vienna. 


\section{Deregulation in Switzerland}

The signing of the Insurance Agreement between Switzerland and the EEC, and the enactment of the relevant implementing legislation, has ushered deregulation into Switzerland. One effect of this is that the concept of the large risk, in the sense of the EC definition of the word, has been introduced in the area of direct non-life insurance. From the 1st January this year (1993), Switzerland too allows extensive freedom of contract between insurance companies and those insureds who qualify as large risks. The fully or partially peremptory regulations of insurance contract law must, of course, be complied with. Equally unchanged is the obligation that premium rates for large risks must neither be so low as to endanger solvency margins nor place an excessive burden on the customer (which, it has to be said, appears to be an extremely rare occurrence with these customers). However, the most significant change for us is that the standard premium tariffs and General Insurance Conditions no longer require the prior authorization of the supervisory authority. Under the new system we no longer have to be given these tariffs and General Insurance Conditions - only carry out sample-checks on them. Naturally all relevant information has to be made available to us when we carry out these sample-checks.

Following on from the large risks, 1994 will also see the abolition of obligatory approval of tariffs and General Insurance Conditions for a whole range of mass risks in Switzerland. In the new circumstances, systematic prior approval of tariffs and General Insurance Conditions is only required for life assurance, sickness insurance and those insurance contracts that are compulsory at national or canton level. This fundamental change in the supervisory philosophy that has existed in Switzerland for over a hundred years, is not an explicit provision of the law. Nevertheless the Federal Council was delegated the competency by Parliament to decide which part of an insurance company's business plan requires official approval. Thus the Federal Council can determine which tariffs and General Insurance Conditions will continue to require approval in the future.

These resolutions were all passed before the 6th December 1992 - a date that has subsequently been referred to time and again in Switzerland. On that day the referendum on Switzerland's proposed entry into the European Economic Area was held. The nation returned a 'no' vote - one of the greatest disappointments experienced by the Swiss government in recent times.

Immediately after the referendum the Swiss government announced that despite the 'no' vote, we should give urgent attention to reviving the Swiss economy - which had become sluggish over the last few decades and, in the government's opinion, set in its ways. At the same time everything possible should be done to make our legislation compatible with Europe. We want to adapt to the developments in the EC and EEA, with the goal of being open to all European political options; also to indicate to the EC our serious interest in further talks.

In this connection, Swiss insurance law has just been harmonised with the 2nd generation of EC directives, in so far as this had not already taken place through the Insurance Agreement between Switzerland and the EEC. Everything that can be introduced autonomously has been passed into law. However, this has not resulted in a unilateral opening of the market: the introduction of freedom of services for large risks - and all the consequential regulations - is conditional upon Switzerland being allowed corresponding rights by other countries involved. For instance, regulations concerning choice of jurisdiction, 
right of withdrawal in life assurance etc. are identical to those in the EC. The former system of material supervision will be largely dispensed with. Although we remain committed to the principle of material supervision, we are turning to other methods.

It should also be noted in passing that the abolition of compulsory prior approval for tariffs and conditions concerning large risks also gives effect to a recommendation made by the Swiss Cartels Supervisory Authority, the Swiss Cartels Commission in connection with their investigation of the Swiss non-life insurance market in 1988.

In this connection we can see a fundamental step towards deregulation in the private insurance market. Following the 1988 recommendation of the Swiss Cartels Commission for the Swiss non-life insurance market, all the important tariff agreement cartels of the Swiss insurance industry have in recent years been disbanded. Generally speaking in many areas there is a steadily decreasing number of standardised tariffs and products, particularly the mass market sector. The market is now offering the consumer a wider choice, but it has also become less transparent and the comparison of products, and even more so of prices, increasingly difficult.

The Insurance Agreement of 1st January 1993 removed the requirement for deposits a matter of particular significance to foreign insurers from the EC countries. Deposits are seen as a form of discrimination and contrary to the principle of freedom of establishment; we have replaced them with the so-called committed assets, which every non-life insurance company has to set aside from the remainder of the assets. In the event of the winding-up of a company, they constitute a separate estate and must be used foremost to cover policyholders' claims.

As a final word on the subject of deregulation in Switzerland, it should also be mentioned that we have now adopted the concept of the solvency margin as a way of measuring a company's solvency. Originally this concept came from the OECD and was taken over by the EC in its insurance directives. The solvency margin is evidence that an insurance company meets the minimum criteria for solvency and represents the minimum limit that must be maintained by its free capital. A company that maintains this limit is, legally speaking, solvent, but that is all that can be concluded from the solvency margin as currently defined. A company that just meets its solvency margin can still be in a financially precarious position. The EC definition of solvency margins is too simplistic a method to measure an insurer's true financial strength or weakness. It is insufficient on its own to merit a 'Triple A' from a rating company.

The concept of the solvency margin was introduced in Switzerland on the 1st January 1993 for non-life insurance, and will probably apply to life assurance from 1st January 1994.

Deregulation has been taken a step further in the area of legal expenses insurance. For decades in Switzerland the principle of specialisation by branches has applied, under which legal expenses insurance could only be transacted by specialist companies. This distinction has been removed by the Insurance Agreement between Switzerland and the EC from the 1st January. Subject to approval and the fulfilment of certain organisational preconditions, legal expenses cover can now be transacted by all non-life insurers. However, this move has met with very little enthusiasm so far.

\section{Regulation consequent upon deregulation}

As a consequence of the deregulation and liberalisation in line with developments in Europe, there are certain areas that now require additional supervision. Two examples of 
this are credit insurance and fire and natural forces insurance. As a result of the Insurance Agreement, a special equalization reserve has to be set up for credit insurance. Until now this was not the practice in Switzerland, as credit insurance reserves were treated in the same manner as other reserves.

Fire and natural forces insurance, which has operated in Switzerland on a voluntary basis for 50 years, must now be regulated by new legislation. The collapse of the non-life insurance cartel and the imminence of cross-border freedom of services both threaten the cooperation that has until now existed between insurance companies in the area of non-life insurance. This cooperation was a precondition for the insurance of fire and natural forces and this function must now be taken over by the authorities.

The setting-up of so-called committed assets is a further example of deregulation resulting in additional regulation. The Insurance Agreement prohibits deposits, which are seen as a form of discrimination against foreign insurance companies, despite the fact that their primary function has always been to protect the interests of the policyholders. Deposits are no longer required from Swiss and EC based companies and have been replaced by a new system of protection, which is non-normative in terms of its approach and as an expression. The committed assets serve to cover the technical reserves for outstanding claims and unearned premiums. In the event of a company going into bankruptcy, it is separated from the rest of the assets.

\section{The effects of deregulation on insurance supervision}

Put briefly, the two basic purposes of insurance supervision are: firstly to protect the insured against being misled into buying an unsound product or paying an excessive premium; secondly to ensure that insurance companies are solvent and will remain so in the foreseeable future, as they must always be able to fulfil their obligations to their policyholders.

In Switzerland the traditional approach to solvency supervision is based on the following:

Minimum capital requirement when a company is formed: depending on which classes of insurance are carried on, the paid-up sum has to be between $0.6 \mathrm{~m}$ and $10 \mathrm{~m}$ Swiss Francs.

Organisation funds on commencement of business, which must lie in a range of between $20 \%$ and $50 \%$ of the paid-up capital and whose purpose is to cover the formation, organisation and development costs of the new company; additionally, initial expected losses should be financed by this fund.

Legal reserves, which have to be built up at a faster rate than is required in the Swiss Company Law for non insurance companies.

Reinsurance appropriate to the company's development.

Obligatory prior approval of the rating structure. Premium rates must receive the approval of the Federal Office of Private Insurance before they can be implemented. The Office must be satisfied that the premium income deriving from the rating structure will remain within reasonable limits, which on the one hand ensure the company's solvency and on the other do not place an excessive burden on the insured. Though these limits are, by definition, very wide, they are completely in accordance with the legislator's intentions.

Technical reserves are to be set up on the basis of methods approved by the supervisory authority before the commencement of business. Naturally this basis can be changed 
in the course of time - albeit only with the supervisory authority's prior approval. We cannot tell whether the reserves for individual cases in non-life policy are correct, nor what the final settlements will be, even less the speed of settlement. Only in motor liability insurance do we know the extent of equalization reserves. In life assurance on the other hand, the technical reserves (actuarial reserves and the equalization reserves for risk insurances) can be accurately determined from the business plan - in the case of the actuarial reserves even policy by policy. Here the problem lies in the great number of policies, which only permits sample-checking.

Investments: the increasing impact of stock exchange and currency fluctuations, the increasing danger of insolvency of borrowers (debentures and loan debtors) and, in the area of non-life insurance, covering technical losses by investment income, all result in investment risks increasingly affecting an insurance company's solvency. The supervisor endeavours to keep these risks within bounds by means of special investment and valuation regulations. The use of derivative financial instruments cannot be monitored; it is scarcely possible for us to determine how this influences a company's solvency.

Apart from these individual elements (some of which are of a fairly rudimentary nature), there is also the supervisory authority's general brief. We are legally obliged to supervise all aspects of an insurance company's business operations. In particular, this includes a company's organisation and management - for the entire period of its existence. Supervision is not simply a matter of obtaining an organigram once a year and filing it. We can, and indeed must, check that this organigram is valid. Of course we do not claim the ability to determine the suitability of an organisation a priory as management consultants. It is more a matter of first of all considering whether deficiencies that come to light later on (e.g. due to complaints) could be the result of organisational shortcomings. We must also satisfy ourselves that a company's managers are 'fit and proper'. We must intervene if a company is being mismanaged. These questions of organisation and management in particular have been badly neglected in the past.

You will see from this, that our Swiss supervisory system is founded on the principle of material supervision. This has been the case since the system was inaugurated over 100 years ago. Material supervision is more comprehensive than, for instance, normative supervision or the system of "Freedom with Publicity". As indicated, controls are not limited to formalities. Instead a detailed material examination of every insurance institution's business operations is carried out, both at the time of initial authorization and throughout its subsequent activity. This on-going supervision means that all changes to the technical and financial bases must be approved by the supervisory authority. The insurance institution is monitored to ensure that it can always meet its obligations, particular attention being given to the returns that have to be submitted annually. It is important that the supervisory authority can, at any time, intervene in the management of an insurance institution, if this is necessary to safeguard the policyholders' interests.

At the present time, deficiencies are becoming apparent in the material system of supervision. In addition, the obligatory prior approval of premium rates, which was a significant feature of the Swiss supervisory system, has now been discarded. However, this certainly does not signify the abandonment of the principle of material supervision. Switzerland will continue to remain committed to the idea of material supervision, although it must be improved. The mode of direct consumer protection will shift too: whercas until now this was centred on prior product approval, it will in future be more closely connected 
with the control of solvency. It is certainly possible that in the future questionable products could appear on the market, or that we will see premium rates so low as to endanger solvency or so high as to exploit the customer. However, in future, the Supervisory Office will only be able to correct such situations after the event, instead of taking preventive action beforehand. It will scarcely be possible to remedy an unsatisfactory state of affairs directly with the company in question. One way of reducing these dangers to a minimum would be for us to obtain a description of all new policy conditions and premium rates in advance of their implementation, which would give us the option of either systematically examining them all, or carrying out sample-checks. As long as such a system were not linked to compulsory prior approval, it would not presumably conflict with EC law. It is also conceivable that certain obligatory minimum standards could be set up, with which rating structures and technical reserves calculations would have to comply. However, we wonder whether another, probably more liberal approach would not possible, instead of renewed technical regulations. Accepting that in future once the state ceases to regulate and approve premium rates, price fixing in the insurance industry will be subject to a certain degree of arbitrariness, competition will sometimes prevent a product from being correctly priced, from a technical point of view. More so than at present, prices will have to be aligned with those of the competition. In overall terms, however, an insurance company should continue to conduct its business on tried and tested technical principles. We wonder whether in Switzerland the actuary's role in a company should not be greater. An actuary should be responsible to the supervisor for the application of the correct technical approach within a company, not only in the area of life assurance, but also non-life insurance and reinsurance. His responsibility could be two-fold: making sure that inadequate premiums do not endanger the company's solvency as a whole and also that individual premiums do not exploit the customer. This responsibility could not be restricted to premiums alone, but would have to extend to the vitally important task of setting up correct reserves. For its part, the supervisory authority would limit itself to sample-checks. As retrospective supervision in a deregulated market can never be as effective as systematic prior control in a regulated market, the insurance industry should be strongly encouraged to take greater responsibility for its own activities.

Another element of a revised Swiss supervisory strategy concerns the way in which accounts are drawn up, both for external and internal use. Internal accounts in non-life insurance are based on a 40 year old format, devised for the market conditions of the immediate post war period. They must be brought into line with the needs of the current situation as a matter of urgency. The data on technical reserves, which is at present rudimentary should be made more comprehensive and should make it possible to asses the claims development. Information on business results abroad should be geared to future home country supervision. The internal accounts should allow a more accurate assessment of solvency than is possible at the moment and must be the basis for modern external accounting procedures. Our intention is to come closer to the EC requirements, as laid down in the accounts directives.

Finally, reference should be made to a supporting measure, that we in Switzerland have in mind. It is nothing new and corresponds to the philosophy that was developed in the EC as well. With the ending of the system of prior product approval on the one hand, and the practically simultaneous dismantling of the cartels on the other, the insurance scene will unquestionably be altered. The consumer will increasingly be faced with choosing from a 
large number of different products; covers will no longer be identical and prices will differ a great deal. Even if the pressures of competition result in products becoming simpler and easier to compare again, it will be very difficult for the consumer to find the product that is best for him. He will become more reliant on professional advice. This is not something that the consumer protection organisations will be able to provide him with. Product and price comparisons will only deal with some of the points, as is the case today, and will be of relatively little use to the buyer of insurance when needed. By contrast, the importance of the professional insurance intermediary in the Swiss market also will increase significantly compared to the present. We should ensure that the buyer of insurance has the best prospects of getting sound advice. Only those with a proper technical understanding of insurance and a good knowledge of the market should be allowed to become insurance intermediaries; they must do more than simply putting the customer and the insurance company in touch with each other.

\section{Conclusion}

The top priority of the insurance supervisory authority remains to protect the policyholder against excessive premiums or the danger of 'his' insurance company becoming insolvent; it will continue to do this in a changed environment and in different conditions. We are not alone in Europe with these views. On the contrary, Europe's insurance supervisory authorities are unanimous in the opinion that the proper measurement of technical reserves and prudent evaluation of assets are the bases for controlling solvency and that actuarial methods must also be applied to non-life insurance.

We can conclude that supervision has been distinctly weakened by the removal of the obligatory prior product controls, particularly in the area of non-life insurance in Switzerland. However, supervision should still continue to be carried out on a material basis. To achieve this the existing elements of supervision will be improved and restructured in the future. Overall, supervision will become a more complex task and will therefore have to be carried out in a more discriminatory manner. 